\title{
A INTERPRETAÇÃO DA CONSTITUIÇÃO E O MÉTODO TÓPICO ORIENTADO AO PROBLEMA - UMA ANÁLISE SOBRE A APLICAÇÃO DA TÓPICA DE VIEHWEG NA JURISDIÇÃO BRASILEIRA COMO GARANTIA DOS DIREITOS FUNDAMENTAIS
}

\author{
THE INTERPRETATION OF THE CONSTITUTION AND METHOD \\ TOPIC ORIENTED TO PROBLEM - AN ANALYSIS OF THE \\ APPLICATION OF TOPICAL VIEHWEG OF THE BRAZILIAN \\ JURISDICTION AS A GUARANTEE OF FUNDAMENTAL RIGHTS
}

${ }^{1}$ Paulo Cesar de Freitas

\begin{abstract}
RESUMO
O presente trabalho tem como objetivo analisar se o método tópico orientado ao problema, resgatado na década de 50 do século XX pelo jurista e filósofo alemão Theodor Viehweg, constitui alternativa capaz de suprir a insuficiência da hermenêutica clássica em matéria de interpretação da Constituição e concretização dos direitos e garantias fundamentais e verificar a compatibilidade de seus preceitos com a noção de sistema jurídico e, ainda, se em menor ou maior grau a tópica é ou pode ser aplicada à realidade jurídico-constitucional brasileira.
\end{abstract}

PALAVRAS-CHAVE: Tópica; Argumentação jurídica; Pós-positivismo;

Neoconstitucionalismo

\begin{abstract}
The present work aims to analyse whether the topic problem-oriented method, rescued in the second half of the twentieth century by jurist and philosopher Theodor Viehweg, constitutes an alternative able to meet the insufficiency of classical Hermeneutics in relation to interpretation of the Constitution and implementation of fundamental rights and fundamental guarantees and check the compatibility of your precepts with the notion of legal system and, yet, if to a lesser or greater degree the topical is or can be applied to Brazilian constitutional and legal reality.
\end{abstract}

KEYWORDS: Topical; Legal argument; Post-positivism; Neoconstitucionalism

\footnotetext{
${ }^{1}$ Mestre em Direito Público pela Universidade Federal de Uberlândia - UFU, Minas Gerais, MG, (Brasil). Especialista em Direito Processual Penal e em Direito Constitucional. Pós-graduando pela Universidade de Salamanca, (Espanha). E-mail: promotorpaulofreitas@gmail.com.
} 


\section{INTRODUÇÃO}

A partir da segunda metade do século XX, com a derrocada do nazismo e do fascismo e tomando como base as atrocidades patrocinadas por esses nefandos regimes governamentais, diversas correntes do pensamento puseram-se a desenvolver modernas teorias, hodiernamente rotuladas de pós-positivistas, todas elas, por mais díspares, contendo um ingrediente comum: apresentar uma solução para os problemas de interpretação da Constituição e para a concretização dos direitos fundamentais ante a evidente insuficiência dos métodos hermenêuticos clássicos, em especial daqueles baseados na lógica formal fruto do positivismo normativista.

O método baseado na lógica-formal-dedutiva de compreender e interpretar o direito e a fórmula da concretização das normas pela via da simples subsunção, a partir do entendimento de que o ordenamento jurídico, dotado de plenitude, conteria as soluções para todos os casos, resta de todo superado, notadamente quando se está diante de um caso de difícil solução.

Com a ideia da superação do paradigma positivista, vê-se ruir, outrossim, a equivocada tese de que a Justiça é valor imanente ao Direito, inserta já em seu conteúdo, o que dispensaria qualquer tipo de valoração a partir de conceitos extrajurídicos. O Direito posto deixa, então, de ser visto exclusivamente como uma realidade dada, pronta e acabada, como o produto de uma autoridade e passa a ser encarado como uma prática social que incorpora uma pretensão de correção ou de justificação. (ATIENZA, 2013, p. 29)

Nesse contexto surgem as teorias da argumentação jurídica e, com elas, são apresentados novos paradigmas de interpretação do Direito e da Constituição. O presente trabalho, tomando como ponto de partida essa mudança de paradigma, tem como objetivo realizar um breve estudo da tópica, a arte de interpretar o Direito a partir do problema. A teoria, proposta por Theodor Viehweg na obra "Tópica e jurisprudência: uma contribuição à investigação dos fundamentos jurídico-científicos “, publicada pela primeira vez em 1953, como sua tese de livre-docência, inspira-se nas obras de Cícero e Aristóteles e busca, em verdade, promover o resgate da ars inveniendi difundida na antiguidade pelos dois grandes pensadores. Precursora das modernas teorias da argumentação jurídica, a tópica adota a lógica do provável, resgatando a argumentação retórica, dialética, em contraposição à lógica analítica norteadora do conhecimento apodítico. 
Pretende-se, no presente trabalho, analisar se a tópica é capaz de fornecer as ferramentas necessárias à argumentação jurídica, se consiste ela realmente em uma fórmula eficaz de concretização do direito, em especial das normas de atuação dos direitos fundamentais e até que ponto esta teoria poderia ser importada e aplicada ao ordenamento jurídico brasileiro.

\section{O NeOCONSTITUCIONALISMO E A SUPERAÇÃo DOS PARAdigMAS JUSNATURALISTA E POSITIVISTA}

\subsection{Pós-positivismo e neoconstitucionalismo}

Durante séculos, com a superação do paradigma jusnaturalista, o dogma positivista imperou. O Direito não comportaria nenhuma valoração com base em elementos meta ou extrajurídicos, promoveu-se a separação radical entre o Direito e a Moral e o simples fato de restarem positivadas, escritas, desde que produzidas pela autoridade competente e de acordo com o procedimento previamente estabelecido, as normas jurídicas deveriam ser observadas porque existentes, formalmente válidas e a expressão da Justiça. Ao intérprete não restaria nenhum espaço para a criação ou correção material do Direito, cabendo-lhe apenas a tarefa de interpretar a lei, com base nos métodos hermenêuticos clássicos, extrair dela o seu sentido e alcance e aplicá-la ao caso concreto, a partir de um raciocínio lógico-silogístico. Não era tarefa do juiz questionar se a lei era justa ou injusta, mas tão somente aplicá-la de acordo com a vontade estatal nela veiculada.

Não obstante, especialmente a partir da segunda metade do século XX, com a extinção dos regimes nazi-fascistas, tem início o declínio do modelo positivista. Ficou evidente, a partir das atrocidades cometidas pelo Estado nazista e fascista em nome da lei, que nem sempre Direito positivado é sinônimo de Direito justo. Ao contrário, no mais das vezes as leis escritas servem apenas de veículos para as pretensões pessoais ou partidárias dos detentores do Poder, como claramente se verificou, a guisa de ilustração, na Alemanha nazista.

O marco teórico do que se considera a superação do paradigma positivista é o póspositivismo, rótulo sob o qual se abrigam diversas teorias que tentam demonstrar, em linhas gerais, que a validade de um ordenamento jurídico pressupõe a inserção, em seus ditames, de 
uma pretensão de correção material; que a tarefa do intérprete do Direito vai muito além da simples subsunção lógico-matemática de um fato jurígeno a uma determinada lei expressa; que o direito deve ser criado e recriado no momento de sua aplicação ao caso concreto, a partir de argumentos racionalmente fundamentados.

Pós-positivismo é conceito que, a seu turno, encontra abrigo na expressão mais ampla neoconstitucionalismo. Neoconstitucionalismo, como nova forma de se pensar o direito, na teoria jurídica e na prática dos tribunais, abriga tanto teorias pós-positivistas, como teorias positivistas, embora nitidamente se possa verificar a abrangência de doutrinas desapegadas do normativismo positivista, notadamente de suas correntes mais radicais.

Como explica Daniel Sarmento (2014), neoconstitucionalismo é a designação que vem sendo emprestada a um novo paradigma emergente no Direito Brasileiro, a partir de um conceito elaborado na Espanha e na Itália e que é responsável por profundas mudanças tanto na teoria como na prática jurídica dos tribunais. As principais mudanças acarretadas pelo neoconstitucionalismo, segundo o renomado autor envolveriam vários fenômenos diferentes, dentre eles a) reconhecimento da força normativa dos princípios jurídicos e valorização da sua importância no processo de aplicação do Direito e a constitucionalização do Direito, com a irradiação das normas e valores constitucionais, sobretudo os relacionados aos direitos fundamentais, para todos os ramos do ordenamento. (SARMENTO, 2014, p. 2).

\subsection{O neoconstitucionalismo no Brasil}

Sarmento (2014) esclarece que o primeiro momento para o aparecimento do neoconstitucionalismo na doutrina brasileira ocorreu logo após o advento da Constituição Federal de 1988 e consistiu justamente no fato de parte dos doutrinadores começarem a advogar a tese da força normativa da Constituição.

Um outro ponto fulcral dessa mudança paradigmática, ao lado da sedimentação do reconhecimento da força normativa da constituição, é o reposicionamento dos princípios dentro do ordenamento jurídico e a consideração também do seu caráter normativo. Os princípios perdem o status de meros adornos e passam a ser definitivamente considerados como uma das espécies de normas, ao lado das regras.

O reconhecimento da força normativa dos princípios passa necessariamente por sua redefinição e realocação dentro do sistema jurídico e, em especial, pela diferenciação entre 
princípios e regras, contributo dado nos tempos atuais por Robert Alexy, muito embora já tivesse suas bases vindo sendo desenvolvidas anteriormente. (2008)

Consoante a lição de Barroso (2013, p. 226), após longo processo evolutivo, consolidou-se na teoria do Direito a ideia de que a norma jurídica é um gênero que comporta, em meio a outras classificações, duas grandes espécies, as regras e os princípios. Em outras palavras, princípio seria uma subspécie do gênero norma, possuindo, portanto, força normativa e não meramente programática, assim como as regras, embora destas últimas se diferencie.

Para Robert Alexy (1997, p. 86), em sua clássica teoria dos direitos fundamentais, a distinção entre princípios e regras, ambos como categorias, espécíes do gênero normas jurídicas, é ponto fulcral e decisivo a fim de caracterizar o princípio não como uma mera aspiração a ser observada pelo operador do Direito de acordo com sua livre oportunidade e conveniência, mas como verdadeira norma, mandado de otimização, de observância cogente: "El punto decisive para la distinction entre reglas y principios es que los principios son normas que ordenam que algo seja realizado na mayor medida possible [...]". (ALEXY, 1997, p. 86)

As normas constitucionais - princípios e regras - assim, conforme adverte Barroso (2013, p. 78), como qualquer outra norma contêm um mandamento, uma prescrição, uma ordem, com força jurídica e não apenas moral. Assim, tem-se que, a inobservância dos princípios, como normas constitucionais que são "há de deflagrar um mecanismo próprio de coação, de cumprimento forçado, apto a garantir-lhe a imperatividade, inclusive pelo estabelecimento das consequências da insubmissão ao seu comando“. (BARROSO, 2013, p. 78)

O pós-positivismo constitucional contagiou a doutrina brasileira por meio das obras de diversos autores, apontados como seus expoentes - malgrado muitos deles não se autointitulem neoconstitucionalistas - tais como Robert Alexy, Ronald Dworkin, John Rawls, Jurgen Habermas, dentre tantos outros.

A partir dessa mudança de paradigma, pelo menos na seara doutrinária, o constitucionalismo brasileiro sofre uma verdadeira revolução. Fica evidente a necessidade de se adotar o novo paradigma, que "já não mais se assenta apenas em um modelo de regras e de subsunção, nem na tentativa de ocultar o papel criativo de juízes e tribunais.“ (BARROSO, 2013, p. 289) 
Mas não se pode negar que a evolução, no Brasil, em direção ao neoconstitucionalismo, não só chegou um pouco tarde, se comparada aos demais países, em especial a Itália e a Espanha, como se dá de forma lenta e gradual. Reconhecidas por parte importante da doutrina, que desde então "passa a enfatizar o caráter normativo e a importância dos princípios constitucionais, e a estudar as peculiaridades da sua aplicação“ (SARMENTO, 2009, p. 289), as mudanças de paradigma fruto do neoconsticionalismo e do pós-positivismo são, ainda, muito pouco exploradas pela jurisprudência de nossos tribunais, incluindo os pretórios superiores.

É possível afirmar, então, que malgrado arraigado na doutrina do Direito Constitucional brasileiro, os preceitos do neoconstitucionalismo ainda não contagiaram, como deveria, a prática de nossos Tribunais.

\section{TEORIAS DA ARGUMENTAÇÃO JURÍdiCA E OS NOVOS MÉTODOS DE RACIONALIZAÇÃO DO PROCESSO DE INTERPRETAÇÃO E DE APLICAÇÃO DO DIREITO}

Dentre as teorias jurídicas contemporâneas que podem ser inseridas no que se convencionou chamar de neoconstitucionalismo não-positivista, destacam-se as teorias da argumentação jurídica. São várias as teorias ligadas ao enfoque argumentativo do Direito, com diferentes concepções, mas todas, contudo, com algo em comum: “[...] a rejeição do modelo da lógica dedutiva.“ (ATIENZA, 2003, p. 118).

Atienza (2003) observa que durante as duas últimas décadas do século XX o estudo da argumentação jurídica constituiu, sem dúvida, um dos principais centros de interesse da atual teoria e filosofia do Direito. Para o autor, de certo modo, a teoria da argumentação jurídica é a versão contemporânea da velha questão do método jurídico.

Dentre as principais teorias da argumentação jurídica, introduzidas pelo póspositivismo e que consubstanciam os novos métodos que visam a racionalização do processo de interpretação e de aplicação do Direito, destacam-se a nova retórica de Chaim Perelman, a lógica-informal de Toulmin, a tópica de Theodor Viehweg e as teorias da argumentação de Robert Alexy e de Neil MacCormick.

Sem a pretensão de esgotar o tema, apresentar-se-á, ora, um rápido panorama dos fundamentos basilares destas principais teorias da argumentação jurídica, à exceção da tópica, 
de Theodor Viehweg, que será tratada de forma mais detalhada no capítulo seguinte, uma vez que esta teoria se insere no ponto central deste escorço jurídico.

3.1 As teorias da argumentação jurídica de Robert Alexy, MacCormick, Chaim Perelman e Toulmin

Dentre as diversas teorias da argumentação que surgiram nas últimas décadas, “as que têm maior interesse e talvez também as que foram mais discutidas e alcançaram maior difusão“ (ATIENZA, 2003) foram as elaboradas por Robert Alexy e por MacCormick.

MacCormick desenvolve uma teoria integradora da argumentação jurídica, tendo como base a crença de que a argumentação jurídica cumpre uma função de justificação que para ele seria a única capaz de possibilitar a persuasão. A justificação teria como esteio as normas jurídicas em vigor e os fatos estabelecidos, de sorte a indicar as razões que mostrem que a decisão final é a expressão da justiça. O convencimento do auditório - imprescindível para a legitimação da decisão - é buscado a partir de toda uma cadeia argumentativa, marcada pela coerência, passando pela apresentação e aceitação de premissas que conduzirão à aceitação, ao consenso sobre a decisão. Apenas os casos fáceis, para McCormick poderiam ser resolvidos de acordo com o tradicional método dedutivo, sendo certo que os hard cases para serem solucionados dependeriam do emprego da racionalidade, do senso de justiça, da humanidade, da compaixão.

Robert Alexy, a seu turno, tem como elemento de destaque de sua teoria da argumentação jurídica a tese do caso especial. Para Alexy, o discurso jurídico é um caso especial do discurso prático geral. Caso especial porque embora se refira a questões práticas cuja decisão passa por uma pretensão de correção, o discurso jurídico ocorre sob circunstâncias especiais, limitado que é pela lei, pelos conceitos jurídicos, pelas circunstâncias, pela necessidade de se seguir um procedimento legal, assim como limitações de tempo, de espaço, necessidade de concisão, etc. As decisões jurídicas devem ser fruto de uma fundamentação racional, com base no ordenamento jurídico que não será tido como existente se não estiver dotado de uma pretensão de correção. A lei injusta deve ser afastada pelo aplicador do Direito sempre que a injustiça pretender alcançar os seus limites extremos e o método lógico-dedutivo somente será possível quando se estiver diante dos casos fáceis. Os casos difíceis devem ser decididos com base no manejo adequado dos meios disponíveis, 
através do processo de argumentação jurídica. Diversamente dos positivistas, que defendem a tese da separação entre Direito e Moral, para Robert Alexy moral e Direito são conceitos vinculados. Afirma que a Moral determina que o conceito de Direito seja definido de modo que contenha elementos morais. (ALEXY, 2011).

Embora não gozem da mesma projeção que as teorias da argumentação anteriores, não pode deixar de fazer menção às teorias de Chaim Perelman e de Toulmin, dada a sua importância histórica e de seus inegáveis contributos para o procedimento argumentativo e para o desenvolvimento das modernas teorias de maior expressão.

Chaim Perelman, influenciado pro Cícero e Aristóteles, apresenta a nova retórica, que se baseia, em linhas gerais, na ideia de um auditório, de cuja perspectiva os destinatários do discurso são persuadidos ou convencidos, a partir de suas próprias convicções, livres de coação. A solução dos problemas do cotidiano, baseados em valores, é buscada na arte da discussão. O objeto da nova retórica é, desta forma, “o estudo das técnicas discursivas que visam provocar ou aumentar a adesão das mentes às teses apresentadas a seu assentimento. (PERELMAN, 2004, p. 141). Perelman adere à lógica, todavia, diferentemente da lógica matemática neopositivista, a lógica da argumentação seria uma lógica dos valores, do razoável do preferível. Todo discurso argumentativo para Chaim Perelman possui um contexto e um auditório para o qual ele é direcionado. Perelman idealiza, assim, três espécies de auditório, o universal (toda a humanidade), o particular (o partícipe de um diálogo) e o próprio sujeito (processos de auto-conhecimento). Pode-se afirmar que os conceitos-chave a nova retórica de Chaim Perelman são o orador, o auditório e o discurso. O auditório, não obstante, não se trata de um conjunto de ouvintes, mas de um grupo de indivíduos a quem se busca persuadir. A preocupação de Perelman é maior com a adesão dos interlocutores do que com a verdade. É imprescindível, para argumentar, que o orador reflita sobre os argumentos que poderão influenciar um determinado auditório: argumentos quase lógicos, argumentos baseados na estrutura do real e argumentos que fundam a estrutura do real.

Com sua lógica-informal, Toulmin não pretende resgatar a tópica ou a retórica a exemplo de Viehweg e Chaim Perelman, respectivamente. Toulmin refuta por completo a aplicação da lógica formal dedutiva no campo da razão prática, haja vista que para ele a argumentação que a lógica utiliza só se prestaria para o campo da matemática. Toulmin, na verdade, pretende apresentar uma nova concepção da lógica. Apresenta um modelo de argumentação que se desenvolveria em várias etapas - na forma de procedimento - e a 
conclusão se o argumento, ao, final, estaria adequado, ficaria na dependência do contexto histórico, social e disciplinar.

3.2 As principais contribuições das teorias da argumentação jurídica para a aplicação e interpretação do Direito

Ainda no limiar do século XX, a práxis jurídica, marcadamente positivista, orientava-se pela concepção de que o Direito, como toda e qualquer ciência, buscava a verdade das coisas. Ao jurista, como cientista do Direito, reservava-se o papel de encontrar no arcabouço de normas, princípios e conceitos jurídicos de um determinado ordenamento, com base na razão prática, o conhecimento das coisas, que pode ser traduzido como a busca da verdade que deveria ser cientificamente comprovada a partir do instrumental jurídico previamente colocado à sua disposição. Para a solução das mais diversas controvérsias, ao aplicador do Direito, ao responsável pela tomada de decisões, restava apenas a adoção de um procedimento, calcado na lógica-formal, a partir do emprego do método dedutivo, que consistia basicamente no fazer aplicar a norma jurídica previamente cunhada pelo Estado, ao caso concreto, de forma matemática. Á norma (premissa maior), deveria subsumir-se o fato (premissa menor), de onde se extrairia friamente a decisão (conclusão), fruto do silogismo puro. Ao intérprete aplicador do Direito não caberia nenhum tipo de indagação sobre elementos morais, sobre se o resultado da decisão obtido a partir da lógica meramente formal seria justo ou injusto. Em outras palavras, a tarefa criadora do intérprete era de todo limitada, não havendo espaço para a criação, para a valoração, para a busca da decisão mais justa, restando afastada qualquer tipo de pretensão à correção. Em um ordenamento jurídico fechado a solução para todos os casos deveria ser encontrada, sem apelo a nenhum elemento extrajurídico, quer de ordem moral, filosófica ou social.

Com a mudança de paradigma pós-positivista, em especial a partir da introdução dos métodos propostos pelas mais diversas teorias da argumentação jurídica, deixa de existir um método jurídico específico para conhecer e efetivar o Direito e "passa a existir uma gama de métodos, fazendo emergir a noção de que a realização do direito não ocorre em modelos fechados, mas de forma plural e no embate de várias opiniões e pontos de vista, como no decorrer de um diálogo“ (PONTES, 2012). O sistema jurídico passa a ser visto como um sistema aberto de normas e princípios, sistema esse obviamente não dotado de completude, 
mas de uma natural incompletude, haja vista a incapacidade lógica de se prever a solução para todos os problemas, de todas as mais intrincadas ordens. O juiz, por outro lado, deixa de ser um mero executor da vontade fria do legislador e adquire, notadamente nos casos difíceis, a missão de encontrar a melhor e a mais justa solução para o caso concreto, espelhando-se na norma e nos conceitos jurídicos, mas devendo e podendo valorá-los a partir de elementos morais na tarefa criadora do direito. (PONTES, 2002)

Nesse novo cenário, os princípios, como visto, adquirem papel especial, agora na qualidade de verdadeiras normas, de observância obrigatória, sob pena de consequências sancionatórias. As decisões devem ser fruto da criação e do manejo racional dos argumentos, devidamente fundamentadas. As decisões não mais simplesmente brotam de uma simples e mecânica dedução silogística, mas têm como fonte uma árdua e complexa tarefa de análise de pontos de vista e argumentos, de ponderação de princípios, da análise valorativa. Nas palavras de Karl Larenz, citado por Robert Alexy, "ninguém mais pode afirmar seriamente que a aplicação das normas jurídicas não é senão uma subsunção lógica às premissas maiores abstratamente formuladas“. (ALEXY, 2005).

\subsection{Casos fáceis e casos difíceis}

O entendimento atualmente prevalente é o de que existem tanto casos fáceis, como casos difíceis. Em muitos casos, talvez a maioria deles, a solução poderá mesmo ser encontrada no ordenamento jurídico, de forma simples, clara e segura. Nesses casos, a melhor saída é mesmo a simples aplicação da regra jurídica, a partir da dedução lógica do sistema, tal qual preconizado pelo positivismo jurídico.

Mas se os casos fáceis, afirma Lorenzetti, são resolvidos "mediante a dedução das regras, a solução dos casos difíceis somente não poderá ser encontrada com tamanha facilidade. (LORENZETTI, 2010, p. 159). É nesse contexto que se apresentam as teorias da argumentação jurídica, que procuram apresentar métodos alternativos para a interpretação e aplicação do Direito, em contraposição aos clássicos métodos e instrumentais positivistas, apenas para aquelas situações, mais complexas, em que a resposta não pode ser extraída das regras predispostas no ordenamento jurídico a partir de sua singela aplicação silogística, a partir do emprego da lógica-formal dedutiva. Ou seja, o foco principal destas teorias são os casos difíceis. 
Alexy (2005, P. 25), ao desenvolver a sua teoria da argumentação jurídica, também prega a necessidade de se diferenciar os casos fáceis dos casos difíceis, sendo certo que os primeiros continuariam a ser solucionados pela via tradicional da simples dedução dos cânones jurídicos previamente codificados e dispostos hierarquicamente e os demais pelos modernos preceitos das teorias argumentativas.

\section{TÓPICA}

\subsection{A tópica - conceito e aspectos gerais}

A tópica trata-se, em linhas gerais, "de uma técnica do pensamento que está orientada para o problema. É um método de interpretação que pretende proporcionar orientações e recomendações sobre o modo como se deve comportar numa determinada situação caso não se queira restar sem esperança" diante de um problema. Constitui, pois, "a técnica de pensar problematicamente“. (VIEHWEG, 2008, p. 33-34)

Atienza (2003, p. 49) define a tópica como uma parte da retórica que se caracteriza por três elementos ligados entre si:

[...] por um lado a tópica é, do ponto de vista de seu objeto, uma técnica do pensamento problemático; por outro lado, do ponto de vista do instrumento com que opera, o que se torna central é a noção de topos ou lugar-comum; finalmente, do ponto de vista do tipo de atividade a tópica é uma busca e exame de premissas: o que a caracteriza é ser um modo de pensar no qual a ênfase recai nas premissas, e não nas conclusões.

Problema aqui deve ser compreendido como sinônimo de um hard case, uma aporia, um caso de difícil solução, para o qual inicialmente não é encontrada uma resposta correta dentro das regras predispostas no ordenamento jurídico, pelos meios interpretativos convencionais.

Alexy (2005, p. 36-38), citando G. Otte, aduz que a tópica pode ter três sentidos: uma técnica de busca de premissas, uma teoria sobre a natureza das premissas e uma teoria do uso dessas premissas na fundamentação jurídica.

Canotilho classifica a tópica entre os métodos de interpretação da Constituição, como uma arte da invenção, uma técnica do pensar problemático. Para o constitucionalista 
português, a tópica nada mais é do que um método tópico problemático de interpretação da constituição e que teria como premissas o caráter prático da interpretação, o caráter aberto, fragmentário ou indeterminado das normas constitucionais e a preferência pela discussão do problema em virtude da abertura das normas constitucionais (CANOTILHO, 2000, p. 1.175). A interpretação da Constituição, para Canotilho (2000, P. 1.175), por meio da tópica "reconduzir-se-ia, assim, a um problema aberto de argumentação entre os vários participantes (pluralismo de intérpretes) através da qual se tenta adaptar ou adequar a norma constitucional ao problema concreto“.

Tem sido muito comum, como observa Bockenforde, o recurso ao processo tópico, por diversos ordenamentos jurídicos, no atual estágio do desenvolvimento do constitucionalismo (1993, p. 20).

Mas o recurso ao método tópico, todavia, não necessariamente vem sendo invocado no estrito sentido em que teorizou Viehweg, com a produção de um catálogo de enunciados diretivos, previamente elaborado e a busca de um consenso a partir de um debate sobre os diversos pontos de vista promovido no âmbito de um processo dialético em sua acepção mais pura. A aplicação da Tópica, mesmo em razão das lacunas apontadas pelos críticos na teoria preconizada por Theodor Viehweg, tem se dado muito mais de forma acrítica, com amplas variações a depender da sistematização de cada ordenamento em que é invocada, a começar pela categoria de enunciados, aforismos, princípios e regras que são elevados, em cada ordenamento, à categoria de topoi. O que não afasta, todavia, a necessidade de se estudar, ainda que perfunctoriamente, a tópica tal qual proposta pelo jurista e filósofo alemão.

\subsection{A tópica no pensamento de Theodor Viehweg}

O jurista alemão Theodor Viehweg, considerado por muitos como o pai da tópica moderna, apresentou a sua obra fundadora no início dos anos 50 do século XX, mais precisamente no ano de 1953, como tese de livre-docência na Universidade de Munique, sob o título Tópica e Jurisprudência. Viehweg parte das concepções de Gian Battista Vico (alusão de Vico), que no primeiro decêndio do século XX escreveu uma dissertação por meio da qual contrapunha o método então atual do pensamento e aplicação do Direito - o método crítico, calcado no cartesianismo, que se baseava num primum verum, em pontos de vista que constituiriam a verdade - ao método antigo, que tinha como base a retórica e como seu pano 
de fundo, a tópica, esta que partia de pontos de vista que não constituitiram necessariamente uma verdade absoluta, indiscutível, mas juízos de verossimilhança obtidos a partir do consenso.

Viehweg, inspirado na proposta de Vico, propõe uma moderna teoria da argumentação jurídica, que como as demais busca romper com o radicalismo da lógica-formal positivista. A tópica tem como um de seus pilares a técnica do pensar por problemas, arte que teve seu desenvolvimento, na verdade, iniciado ainda com Aristóteles, e constituiria em uma das seis obras aristotélicas que sucessivamente foram reunidas no Organon (Viehweg, 2008, p. 21). Aristóteles, que foi quem emprestou essa designação (tópica) a esta forma de ars inveniendi, propôs-se a tarefa de encontrar um método com base no qual fosse possível estabelecer conclusões relativamente a todos os problemas apresentados a partir de proposições opináveis. Partindo do problema proposto, a solução deveria ser encontrada em um catálogo de tópicos, de premissas que se traduziriam, grosso modo, em opiniões respeitadas, acreditadas e verossímeis, da qual se pudesse presumir aceitação (VIEHWEG, 2008, p. 24). Cícero, cerca de 300 anos depois, também escreveu a sua tópica, baseada na obra de Aristóteles. A obra de Cícero, segundo o próprio Viehweg, teria tido maior importância histórica (Viehweg, 2008, p. 28) e teve como proposta elaborar um catálogo completo de topoi, diversamente de Aristóteles que propunha uma ordenação teórica dos topoi.

A tópica, portanto, tal qual proposta por Viehweg, tem seu nascedouro na retórica Aristotélica e se apresenta como uma alternativa ao já superado modelo positivista de se pensar e aplicar o Direito, especialmente diante dos casos difíceis. O método positivista, da lógica-formal, da aplicação do Direito limitada à busca de respostas em um ordenamento jurídico fechado e dotado de plenitude, pode muito bem servir à solução dos casos fáceis, mas não se mostra adequado ou suficiente para a solução dos problemas para os quais se apresentam inúmeras possibilidades interpretativas, com mais de uma resposta para o mesmo caso. Diante de uma hipótese fática para a qual se apresentam várias respostas, faz-se necessária a imposição de parâmetros a serem observados pela argumentação jurídica para que ela possa ser considerada válida.

A abertura da Constituição, o seu caráter fragmentário e a indeterminabilidade de suas normas exige até com certa naturalidade o manejo de outros recursos de interpretação muito além da lógica cartesiana e demanda a busca por recursos de interpretação diversos do 
modelo proposto por Savigny e complementado por Ihering, evidentemente insuficiente para a concretização dos direitos fundamentais preconizados nas mais diversas cartas políticas em todo o mundo.

A tópica pressupõe o primado do caso concreto, do problema, sobre a norma e o sistema, diferentemente do que acontece no sistema hermenêutico clássico. $O$ que não significa, todavia, o rompimento com a normatização, com as regras e princípios jurídicos. Estes últimos, antes, formarão, ao lado de tantos outros, um catálogo de topoi, de premissas, de lugares comuns, de enunciados-guia. O caso concreto será, então, amplamente debatido pelos diversos participantes do auditório erguido sob um processo dialógico, discursivo, à luz daquelas premissas (jurisprudência, ciência jurídica, princípios e regras legais e constitucionais, princípios gerais de direito, todos os demais meios de interpretação). A solução mais justa para o caso concreto será extraída do consenso obtido nesta única instância de controle (a discussão) que indicará qual ou quais os pontos de vista deverão preponderar, decorrendo, a validade do Direito e a legitimidade da decisão, desse acordo. Os lugarescomuns, assim, é que fornecerão os elementos para a argumentação jurídica.

Não há, todavia, um conceito claro e objetivo de topos, tampouco foram estabelecidos por Viehweg quais os critérios orientariam a seleção dos topoi. De igual forma, não há um sistema de hierarquia entre os tópicos, nem mesmo qual ou quais deles em determinada circunstância deveriam prevalecer sobre os demais. O processo de argumentação jurídica é que irá conduzir essa prevalência que ocorrerá apenas no caso concreto, como a seleção das premissas também será fruto do processo dialógico argumentativo.

Em se deparando com uma solução teratológica, que cause perplexidade, o processo de discussão será retomada, até que a solução mais justa e razoável seja encontrada.

\subsubsection{Tópica de primeiro grau e tópica de segundo grau}

Tópica de primeiro grau, consoante preconiza Theodor Viehweg, é a tópica que não se ancora em um catálogo predisposto de premissas, de lugares comuns, de pontos de vista. Em outras palavras, a tópica de primeiro grau, diante de cada problema a ser analisado, parte na busca da criação dos tópicos que não necessariamente estarão explícitos, mas que serão ocasionalmente criados sempre que deles se necessitar para a solução do caso concreto. Não há formado um catálogo de topoi, mas o apoio para o deslinde da questão é buscado ocasionalmente em premissas que se afigurem as mais adequadas. 
A tópica de segundo grau, ao contrário, é aquela que procura a premissa adequada em um catálogo de topoi explícito, previamente construído. Ou seja, quando da solução do caso concreto, o melhor sistema é procurado em um repertório pronto de pontos de vista disponíveis.

Como Viehweg não elaborou um catálogo de lugares-comuns, tampouco forneceu, em sua teoria, elementos que possibilitassem, de forma objetiva, esta elaboração, nesse ponto, como se verá, a sua teoria é bastante criticada por vários e importantes teóricos do Direitos. O que não impede, já se adiante, o recurso ao processo tópico, cabendo ao intérprete, em cada realidade dada, encontrar estas premissas no foro discursivo que se constituir como instância de controle e busca da racionalidade.

4.3 A tópica e a interpretação e aplicação da Constituição no sistema jurídico brasileiro

Os principais críticos à proposta formulada por Theodor Viehweg, de resgate da retórica por meio da tópica como alternativa ao modelo positivista baseado na lógica-formal e aos métodos clássicos savignyanos, apontam como pontos negativos principais, a imprecisão de seus conceitos, a incompletude da teoria, em especial porque Viehweg não se dispôs a elaborar o catálogo de topoi por ele tido como essencial à concretização de sua teoria, a possibilidade de esse tipo de interpretação poder conduzir a um casuísmo sem limites e, ainda, o fato de que a interpretação tal qual sugerida pela tópica partiria do problema em direção à norma, quando, na verdade, como uma atividade normativamente vinculada, a interpretação jurídica não admitiria o sacrifício da primazia da norma em prol da prioridade do problema. (CANOTILHO, 2000, p. 1.175).

Malgrado a resistência de parte da ciência jurídica à tópica residir na ideia de que o método não se compatibilizaria com a ideia de sistema que, por sua vez, seria essencial em matéria de hermenêutica constitucional, resulta evidente que a incompatibilidade da tópica não é necessariamente com a noção de sistema, mas, sim, com a compreensão de um sistema jurídico fechado, completo, axiomático e lógico-dedutivo.

Em um sistema jurídico tal qual preconizado pelo positivismo normativista radical, a solução para os conflitos devem ser encontradas ali mesmo no ordenamento jurídico, partindo-se sempre do sistema em direção ao problema e não o contrário. A tarefa do intérprete consiste tão somente em desvendar o objeto "direito" e aplicá-lo a um caso 
concreto, valendo-se, para tanto, da dedução lógico-matemática e do processo subsuntivo. Segundo Viehweg, em um sistema dedutivo, toda proposição usada como premissa será reconduzida a outra e, finalmente, a uma proposição central, que, ao contrário, é derivada dela ou que é ela própria estabelecida como proposição central. (VIEHWEG, 2008).

Para o pensamento tópico-problemático o que se enfatiza não é o sistema, mas o problema e, a partir deste, o será escolhido o sistema que melhor oriente na busca da solução mais justa e adequada. Não há, outrossim, nenhuma ordem lógico-formal entre as premissas, tampouco critérios rígidos de escolha dos pontos de vista objeto da discussão no âmbito do processo dialógico.

Notadamente como critério orientador da prática jurídica, a tópica se apresenta, no constitucionalismo atual, como meio adequado para a interpretação das normas constitucionais. Segundo Paulo Bonavides (1991), “a constituição representa, pois, o campo ideal de intervenção ou aplicação do método tópico.“ Em razão da natureza da Constituição, compreendida em seu aspecto material e não meramente formal, composta por um conjunto de normas abertas, de caráter fragmentário, necessariamente a tarefa de interpretá-la deve ir além dos cânones e métodos hermenêuticos clássicos.

A Constituição integra um sistema, todavia, um sistema aberto de regras e de princípios, e não um sistema fechado, completo, axiomático-dedutivo. Essa norma compreensão de sistema no qual se vê inserida a Constituição, é, portanto, terreno fértil para a tópica, como método concretizador dos direitos e garantias fundamentais.

Adotar o método tópico orientado ao problema, portanto, não corresponde a abrir mão da normatização, tampouco de um sistema jurídico destinado a assegurar positiva e previamente os direitos e garantias fundamentais. O intérprete continuará a buscar a solução para a imensa maioria dos casos nas regras e princípios sistematizados. Nos casos fáceis, o método lógico-formal poderá ser empregado sem nenhuma restrição, haja vista que a solução que puder ser extraída das regras é sempre a mais segura e adequada. Nos casos ineludíveis, quando se estiver diante de uma verdadeira aporia, de um hard case, em que a solução não estiver contemplada em nenhuma regra do ordenamento jurídico de sorte que possa ser simplesmente encontrada pelo intérprete a partir do silogismo ancorado nos critérios hermenêuticos savignyanos, o intérprete dará maior relevo ao problema e partirá dele em busca do melhor sistema de solução, deixando de enfatizar o sistema, sem, contudo, abandonar arbitrariamente o conjunto de regras e princípios integrantes do ordenamento 
jurídico. As normas, in casu, não deixarão de ser consideradas, mas apenas erigidas à categoria de lugares-comuns, de pontos de vista, que ao lado de tantos outros orientarão a tarefa da "sociedade aberta dos intérpretes da Constituição." (HABERLE, 1997).

En sus decisiones fundamentales y normaciones singulares, la Constituición se convierte, con esto, en una combinación de puntos de vista relevantes para la solución de problemas, junto a otros, cuya relevancia en el caso concreto no viene ya determinada por si mesmos, sino por la correspondiente precompreensión consensuada. Esta compreensión ya no es sólo el cuestionamento o la hipótesis com la que se empreende la interpretación constitucional, antes bien, tiene efecto normativo como tal y desde si mesma. (BÖCKENFÖRDE,1996, p. 23)

A tópica, assim, tem tido papel de enorme destaque nos estudos jurídicos no Brasil e no mundo. Métodos de interpretação têm sido desenvolvidos por diversos teóricos, em especial, pelos juristas alemães, que incorporam princípios básicos da teoria de Viehweg. Proliferam, outrossim, artigos jurídicos e trabalhos acadêmicos que contemplam o tema, garantindo-lhe o lugar de destaque no universo do Direito como argumentação.

A partir da democratização da interpretação da Constituição e do reconhecimento de aspecto material, cada vez mais é possível vislumbrar nos mais diversos ordenamentos jurídicos a aplicação de métodos oriundos da tópica quando da concretização das regras e princípios constitucionais. Em menor ou maior grau, destaste, é forçoso concluir que a tópica de Viehweg tem se apresentado como alternativa viável de interpretação do Direito Constitucional, frente a já mencionada insuficiência dos métodos tradicionais.

No sistema brasileiro não poderia ser diferente. A despeito das críticas e dos abalizados entendimentos em sentido contrário, a tópica, tal qual preconizada por Viehweg ou simplesmente como uma técnica de busca de premissas, ou como uma teoria sobre a natureza das premissas, ou, ainda, na forma de uma teoria do uso das premissas na fundamentação jurídica, é perfeitamente compatível com o ordenamento jurídico brasileiro e pode mesmo ser aplicada na concretização da Constituição Federal de 1988, notadamente na efetivação dos direitos e garantias fundamentais nela preconizados.

É claro que críticas como aquelas formuladas por Robert Alexy e Manuel Atienza acerca principalmente da estrutura superficial e da ausência do estabelecimento de hierarquia dos argumentos standard (os topói) e da suposta falta de importância dada pela tópica de Viehweg à lei, à dogmática e ao precedente judicial, não podem ser ignoradas. 
Mas é preciso ter em mente que a par de suas imprecisões terminológicas e das deficiências e lacunas da tópica tal como fora até o momento desenvolvida - debilidades, que, aliás, em menor ou maior grau podem ser verificadas em todas as grandes teorias - não se pode perder de vista que a tópica se trata de uma teoria ideal de aplicação e interpretação do Direito, como solução para a insuficiência dos parâmetros fornecidos pelo positivismo jurídico para a solução dos casos difíceis. E como uma teoria ideal, nada impede que seja ela transposta e aplicada ao Direito brasileiro, ainda que apenas em parte, quanto àqueles aspectos que se compatibilizam com a realidade e com as possibilidades jurídicas e sociais de nosso país.

Prova maior disso é que o Supremo Tribunal Federal, conquanto não o reconheça explicitamente e o faça muitas vezes de forma acrítica, vem adotando a tópica, sistematicamente, quando da resolução dos casos complexos (hard cases).

De fato, antes de proferir a sua decisão final em muitos dos casos de alta indagação julgados ou em julgamento nos últimos anos - união homoafetiva, aborto anencefálico, pesquisas com células tronco embrionárias - o Pretório Excelso promoveu a análise pública do problema e conclamou os mais diversos segmentos sociais a apresentarem os seus pontos de vista sobre os intricados temas.

Resulta claro que ao promover as audiências públicas, colher os mais diversos pareceres técnicos e jurídicos sobre o caso a ser julgado, ao admitir na forma verbal ou escrita argumentos dos mais distintos segmentos sociais, como associações civis, fundações, organizações não governamentais, médicos, juristas, servidores públicos, pessoas comuns do povo, o Supremo Tribunal Federal - STF está se valendo, em menor ou maior grau, dos pressupostos teóricos extraídos da Tópica de Theodor Viehweg.

A Corte Suprema brasileira, com efeito, tem sistematicamente organizado auditórios com diversos partícipes - cidadãos comuns, servidores públicos, órgãos públicos, organismos políticos - e proposto discussão em busca de um consenso sobre a solução mais justa e adequada para determinados casos de difícil solução, para os quais não é possível encontrar, no ordenamento, pelos meios clássicos de interpretação e de subsunção, a regra a ser aplicada. Nesta instância de controle, a sociedade aberta dos intérpretes se orienta a partir de pontos de vista que ainda que não se apresentam formalmente e previamente reunidos em um catálogo de topói, cuidam-se de premissas fruto de longos debates e de precompreensões e largamente utilizadas já com caráter de norma em inúmeros outros precedentes, a saber, princípios de 
interpretação da constituição, princípios gerais de direito, normas constitucionais, regras infraconstitucionais, precedentes jurisprudenciais e doutrinários, que se juntam a tantos outros.

O procedimento adotado pelo STF, como o que se verificou, a guisa de exemplo, no bojo da ADPF 54, nada mais é do que o procedimento proposto pela tópica de Theodor Viehweg: pensar o caso difícil a partir do problema e procurar o melhor sistema para a sua solução em um catálogo de premissas, pontos de vistas, lugares-comuns, construído e/ou discutido através de amplo debate, por um auditório plurissubjetivo. Mesmo sem a necessidade do consenso, esses pontos de vista foram apresentados não como primum verum, não como verdades absolutas, mas como entendimentos dotados de verossimilhança suficientes para orientar a concretização da constituição federal da forma mais justa e adequada. O STF, em outras palavras, buscava, com o procedimento, a legitimação da decisão, a partir da adoção clara da técnica consistente em pensar a partir do problema, orientada por um catálogo de topoi.

Com este proceder, o STF nada mais faz do que colocar em prática a arte de pensar a partir do problema, promovendo, a um só tempo, a busca incansável por premissas, premissas estas que não consubstanciam verdades absolutas, senão que opiniões dotadas de verossimilhança, obtidas a partir do debate plurissubjetivo. Em maior ou menor grau, assim, o Supremo Tribunal Federal tem aplicado em seus julgamentos os pressupostos basilares do método tópico orientado ao problema, a exemplo de outras cortes constitucionais, como o Tribunal Federal Alemão.

\section{CONCLUSÃO}

A tópica, ou simplesmente o método tópico orientado ao problema, embora preconize o primado do caso concreto sobre a norma, não é incompatível com a noção de sistema aberto de normas e princípios constitucionais, senão com a ideia de um sistema jurídico fechado, lógico dedutivo. Apresenta-se, dessa forma, a tópica resgatada por Theodor Viehweg da antiga retórica Aristotélica, como uma importante teoria da argumentação jurídica e como imprescindível instrumento de interpretação da constituição.

Os pressupostos teóricos desenvolvidos por Theodor Vieweg, de fato, encontram terreno fértil no constitucionalismo moderno, em que os métodos hermenêuticos clássicos, 
propostos por Savigny, já não são suficientes para a solução das aporias, dos casos ineludíveis ligados à concretização dos direitos e garantias fundamentais, diante da abertura e indeterminação das normas constitucionais.

Esta constatação tem levado inúmeros teóricos do Direito no mundo todo, notadamente na Alemanha, a desenvolver novos paradigmas de interpretação das normas constitucionais permeados por pressupostos extraídos da tópica de Viehweg. Nessa mesma linha, as Cortes Constitucionais de diversos Estados, de que são exemplo o Brasil e a Alemanha, têm recorrido sistematicamente à tópica como recurso interpretativo das normas constitucionais, como forma de garantir a solução de casos difíceis, envolvendo os direitos humanos positivados em suas Constituições e evitar o non liquet que já não é mais possível diante do constitucionalismo atual.

\section{REFERÊNCIAS}

ALEXY, Robert. Conceito e validade do direito. Tradução de Gergélia Batista de Oliveira Mendes. São Paulo: Martins Fontes, 2011.

ALEXY, Robert. Teoria da argumentação jurídica: a teoria do discurso racional como teoria da fundamentação jurídica. Tradução de Zilda Hutchinson Schild Silva. 3 ed. Rio de Janeiro: Forense, 2005.

ALEXY, Robert. Teoria dos direitos fundamentais. Tradução de Virgílio Afonso da Silva. 5 ed. São Paulo: Malheiros, 2008.

ALEXY, Robert. Teoria de los derechos fundamentales. Madrid: Centro de Estudios Constitucionales, 1997

ATIENZA, Manuel. As razões do direito: teorias da argumentação jurídica. 3 ed. São Paulo: Landy, 2003.

ATIENZA, Manuel. Curso de argumentação jurídica. Madrid: Trotta, 2013.

ATIENZA, Manuel. "O Direito como argumentação." in MOREIRA, Eduardo Ribeiro. Argumentação e estado constitucional. São Paulo: Ícone, 2012, p. 95.

ÁVILA, Humberto. Teoria dos princípios: da definição à aplicação dos princípios jurídicos. São Paulo: Malheiros, 2003.

ÁVILA, Humberto. Segurança jurídica: entre permanência, mudança e realização no Direito Tributário. rev., atual. e ampl. - São Paulo: Malheiros, 2011. 
BARROSO, Luís Roberto. Direito constitucional contemporâneo: os conceitos fundamentais e a construção do novo modelo. 4 ed. São Paulo: Saraiva, 2013.

CANOTILHO, J.J. Gomes. Direito constitucional e teoria da constituição. 4 ed. Almedina, Coimbra, 2000.

HABERLE, Peter. A sociedade aberta dos intérpretes da constituição: contribuição para a interpretação pluralista e procedimental da constituição. (tradução de Gilmar Ferreira Mendes). Porto Alegre: Sérgio Antônio Fabris, 1997.

HESSE, Konrad. A força normativa da constituição (tradução de Gilmar Ferreira Mendes). Porto Alegre: Sérgio Fabris, 1991.

KELSEN, Hans. Teoria pura do direito. 3 ed. São Paulo: Martins Fontes, 1991

LORENZETTI, Ricardo Luis. Teoria da decisão judicial: fundamentos de Direito. Tradução de Bruno Miragem e Cláudia Lima Marques. 2 ed. São Paulo: RT, 2010.

MACHADO, Daniel Carneiro. Considerações sobre a tópica de Theodor Viehweg. Jus navigandi, Teresina, ano 19, n. 3970, 15.5.2014. Disponível em http//jus.com.br/artigos/28467. Acesso em 14.11.2014.

MELlO, Celso Antônio Bandeira de. Curso de Direito Administrativo. 29 ed. São Paulo: Malheiros, 2012.

MOLLER, Max. Teoria geral do neoconstitucionalismo: bases teóricas do constitucionalismo contemporâneo. Por Alegre: Livraria do Advogado, 2011.

PERELMAN, Chäim. Lógica jurídica. Tradução de Vergínia K. Pupi. 2 ed. São Paulo: Martins Fontes, 2004, p. 141.

PONTES, Kassius Diniz da Silva, OUTROS. O raciocínio juridico na filosofia contemporânea: tópica e retórica no pensamento de Theodor Viehweg e Chaim Perelman. São Paulo: Carthago Editorial, 2002, p.

SARMENTO. Daniel. O neoconstitucionalismo no Brasil: riscos e possibilidades. Disponível em http://www.editoraforum.br/sist/conteudo/lista_conteudo.asp?FIDT_CONTEUDO=56993, acesso em 16/07/2014, p. 2.

SARMENTO, Daniel. "O neoconstitucionalismo no brasil. "in QUARESMA, Regina, OUTROS (Coord.). Neoconstitucionalismo. Rio de Janeiro: Forense, 2009.

VIEHWEG, Theodor. Tópica e jurisprudência: uma contribuição à investigação dos fundamentos jurídico-científicos. Tradução de Kelly Susane Alflen da Silva. 5 ed. Porto Alegre: Sérgio Antônio Fabris, 2008. 